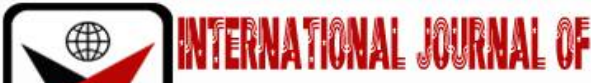

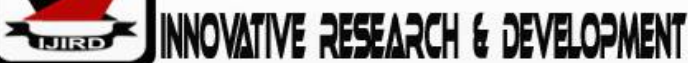

ISSN 2278-0211 (Online)

\section{Strategic Customer Focus and Performance of the Insurance Sector in Rwanda}

\author{
Isabane Sandrine \\ Student, Department of Master's in Business Administration (MBA) \\ Jomo Kenyatta University of Agriculture and Technology, Kenya \\ Mulyungi, Patrick \\ Lecturer, School of Business Studies, \\ Jomo Kenyatta University of Agriculture and Technology, Kenya
}

\begin{abstract}
:
It has been established within the literature that the practice of customer focus strategy is significantly associated with performance of insurance sector. However, the possibility that the attributes of customer focus may affect other relevant measures has not been thoroughly explored. This study investigated the effect of customer focus on performance of the insurance sector in Rwanda. The target population included 8 insurance companies registered in Rwanda with a total of 150 managers all involved with customers. A multi-sampling technique was adopted to obtain 110 managers to represent the 8 insurance companies. A closed ended questionnaire was used to obtain primary data which was then analyzed using the Statistical Package for Social Sciences (SPSS VERSION 21). Cumulatively, 62.96\% respondents were in disagreed that the structure has an effect on the organization performance, while $37 \%$ were in agreement with all attributes about the customer focus strategy on performance of insurance sector. There was an insignificant effect of customer focus strategy on performance because the insurance sector did not grow or expand, I terms of employees and customer base. The study recommends that insurance companies invest more on innovative strategies that would enhance customer focus for the industry to grow in Rwanda.
\end{abstract}

Keywords: Effectiveness, innovation, employees, customer satisfaction

\section{Introduction}

The practice of customer focus strategy has been implemented by various companies, in today's competitive market place, companies around the globe require some form of strategy to enable them to identify the vision, mission, values of the company, the goals how they shall reach there and how they shall know that they have reached (Schlesinger, 2010). Dess, Lumpkin and Taylor (2013) explain that strategic management is a management process consisting of the analysis, decisions and actions a company undertakes in order to create and sustain competitive advantages. It is concerned with the analysis of strategic goals and internal and external environment it enables the management to make decisions on which areas to compete in and how to compete. It enables development of procedures and plans to achieve set goals and to allocate corporate resources to enable the implementation of the plans. These activities enable the organization to be future-oriented; provide direction; enables the organization to strategically fit in the environment it operates; motivates employees as they are involved in various strategic management activities, together with other critical factors such as continuous improvement, teamwork, and management commitment (Abdullah et al., 2008; Yu et al., 2012). The benefits of customer focus strategy had been confirmed in various types of firms,(Mojtahedzadeh and Arumugam, 2011), Although the bottom line of this strategy is to attain customer satisfaction, its effect on insurance sector performance measures, such as financial results and employee satisfaction, also reportedly exist (Anaza and Rutheford, 2012; Chotekorakul and Nelson, 2013).Today customer focus strategies are needed in all types of organizations regardless of their size, at all organization's levels and in all work areas. Because customer focus is widely needed, improving the way an organization is managed is one of the keys to success, and the importance of customer focus strategies to achieve this goal is recognized around the world. In order to answer this research question, this study used a path analysis to test the relationship between customer focus and organizational performance. The rationale behind this hypothesis is that motivation of managers of less competitive sectors to implement customer focus has been shown to be unsatisfactory (Steven et al., 2012). Therefore, this requires further investigation to validate the customer focus strategy on the performance of insurance sectors. This present study was carried out to close this neglected gap.

\section{Literature Review}

The study by Lado etal, (2011) finds a significant relationship between customer focus and financial performance. Another study by Ahire et al, (2013) Confirmed the Sustainable performance refers to an expectation that an organization 
is able to react rapidly and efficiently when faced with emerging customer-related issues, (Mukerjee, 2013)finds that an important factor, given the dynamic nature of customer expectations. Wright (2013) notes that the manner in which service improvement efforts yield increased revenues results to a series of effects. CAI, (2009) confirmed that in order to implement the practice of customer focus successfully, the organization must draw extensively on customer data which typically provides information that enable employees to engage more fully to address customer related issues. Cai, (2013) noted that this strategy may confer positive effects on several other performance measures which are mentioned below: Cai, (2009),a successful implementation of customer focus would require the relevant organization to improve the way they are doing their production this, in turn, would probably bring about greater effectiveness and innovation within the organization,(Mokhtar, (2013); Slater and Narver, (2010); the strategy of customer focus is most likely of value to the customer by ultimately improving the overall quality of the products. Kim et al., 2012 \& Mukerjee, 2013) find that the innovation is arguably more prevalent within firms that emphasize customer-oriented strategies, Yu et al., (2012) noted that there is a need for more research which focuses on how a culture of customer first operates within public firms. (Aziz and Ennew, 2013) finds that an essential attribute that contributes to high levels of employee satisfaction. (Alam, (2013) confirmed that an effective interaction with customers had been reported as a key for an organization to be an innovative organization. Krivokapic et al., (2013) note that it requires the organization to continually seek new ways of doing and managing all matters, thus resulting in the innovation of products, processes, and ultimately the organization. Verhoef and Lemon, (2013) firms implementing a customer focus strategy would be able to strengthen the processes involved in producing products or delivering services. Tajeddini et al., (2013) noted that the ultimate objective of customer focus is fulfilling customer expectation therefore its relationship with customer satisfaction needs to be gauged. In implementing customer focus strategy, the organization needs to provide vast opportunities for customers to provide feedback and suggestion. Zhu et al., (2010) finds that the output that contains quality features can only contribute towards higher levels of customer satisfaction. Pan et al., (2012). In addition, customer involvement in assuring the quality of product of service would install positive perception among customers, a factor that had been proven to lead to increased customer satisfaction. There is a relationship between customer focus and customer satisfaction.

\section{Methodology}

A survey was conducted using a questionnaire administered to 110 employees drawn from 8 insurance firms registered in Rwanda. Data obtained was analyzed for both descriptive and inferential statistics using SPSS statistical package and presented in form of appropriate frequency tables and charts.

\section{Results and Findings}

\subsection{Work Experience}

Table 1 illustrates the distribution of the respondents based on work experience. More than $56 \%$ of respondents have had work experience of between three and five years

\begin{tabular}{|c|c|c|}
\hline Respondent Work Experience & Frequency & Percentage \\
\hline More 7 years & 18 & $17 \%$ \\
\hline Between 3-5 years & 60 & $56 \%$ \\
\hline Less than 2 years & 30 & $28 \%$ \\
\hline \multicolumn{2}{|c|}{ Table 1: Distribution of Respondents by Work Experience }
\end{tabular}

\subsection{Customer Focus Measurements}

Meanwhile, Table 2 reports the mean values and standard deviations. The minimum and maximum scores for all constructs are one and five, respectively. These scores were measured using a one-to-five-point scale.

\begin{tabular}{|c|c|c|}
\hline Concept & Mean & Standard Deviation \\
\hline $\begin{array}{c}\text { Customer focus- effectiveness and } \\
\text { innovation }\end{array}$ & 3.5 & 0.615 \\
\hline Customer focus- employee satisfaction & 3.6 & 0.550 \\
\hline Customer focus- customer satisfaction & 3.4 & 0.514 \\
\hline
\end{tabular}

Table 2: Descriptive Statistics of Concepts

Table 3 set out the results of the reliability and validity tests, which indicates that all concepts have acceptable reliability levels of above 0.70 (Nunnaly and Bernstein, 1994). Table 3 also shows that all items attached to their relevant constructs are measuring what they are supposed to be measuring, based on the factor loading values of above 0.30 (Hair et al., 1998). 


\begin{tabular}{|c|c|c|c|c|c|}
\hline & Kmo & Factor Loading & Eigenvalue & \% of Variance & Alpha Coefficient \\
\hline Customer focus & 0.812 & $0.739-0.835$ & 2.849 & $57.83 \%$ & 0.7610 \\
\hline $\begin{array}{c}\text { Effectiveness \& } \\
\text { innovation }\end{array}$ & 0.751 & $0.643-0.825$ & 2.497 & $61.025 \%$ & 0.8134 \\
\hline Empl. satisfaction & 0.675 & $0.781-0.882$ & 1.915 & $67.25 \%$ & 0.7688 \\
\hline Cust. satisfaction & 0.710 & $0.482-0.856$ & 2.119 & $53.975 \%$ & 0.6965 \\
\hline
\end{tabular}

Table 3: Reliability Test and Factor Analysis

The indices of the model suggest goodness of fit, as illustrated in Table 4. The threshold Prescribed by Hair et al. (1998) was referred to in deriving the former conclusion.

\begin{tabular}{|c|c|c|c|}
\hline Goodness of Fit Measures & $\begin{array}{c}\text { Levels of } \\
\text { Acceptable Fit }\end{array}$ & $\begin{array}{c}\text { Acceptable Fit } \\
\text { Indices of Model }\end{array}$ & Acceptability \\
\hline $\begin{array}{l}\text { Chi-square } \\
\text { Chi-square/degrees of freedom } \\
\text { Goodness-of-fit Index (GFI) } \\
\text { Adjusted Goodness-of-fit Index (AGFI) } \\
\text { Tucker Lewis Index (TLI) } \\
\text { Comparative Fit Index (CFI) }\end{array}$ & $\begin{array}{l}P \geq 0.05 \\
\leq 3.00 \\
\geq 0.90 \\
\geq 0.90 \\
\geq 0.90 \\
\geq 0.90\end{array}$ & $\begin{array}{l}P \geq 0.05 \\
\leq 3.00 \\
0.998 \\
\\
0.974 \\
1.002 \\
1.000\end{array}$ & $\begin{array}{l}\text { Yes } \\
\text { Yes } \\
\\
\text { Yes } \\
\text { Yes } \\
\text { Yes } \\
\text { Yes } \\
\text { Yes }\end{array}$ \\
\hline
\end{tabular}

Table 4: Levels of Acceptable Fit of Selected Goodness of Fit Measures

Table 5 reports the results of the hypothesis testing. The prescribed threshold value of a critical ratio of 1.96 (Arbuckle and Worthe, 1999) was used to conclude the testing. Accordingly, H1, H2, and H3 were supported

\begin{tabular}{|c|c|c|c|c|}
\hline Path/ Approaches & S.E & CR & H & Result \\
\hline Effectiveness \& innovation & 0.383 & 6.096 & H1 & supported \\
\hline Employee Satisfaction & 0.628 & 10.543 & H2 & supported \\
\hline Customer Satisfaction & 0.150 & 2.130 & H3 & supported \\
\hline
\end{tabular}

Table 5: Hypothesis Testing S.E-Standardized Estimate; CR-Critical Ratio

\section{Discussions}

The findings of this study are consistent with previous research which suggested that customer focus is typically implemented with positive results on performance of insurance sector (Jacobs and Suckling, 2007), thus validating the appropriateness of customer focus strategy everywhere on different insurance companies in Rwanda. The awareness significant effect of organizational innovation has also been attributed to influence the success of customer focus (Kim et al., 2012; Krivokapic et al., 2013). To increase the overall value gathered from customers in terms of services rendered, insurance sector must explore new ways of operating by reorganize and rearrange those processes which may further stimulate effective innovative thinking amongst employees. Information captured on customer feedback form may offer valuable insights for employees, and facilitate effectiveness and innovation whether gradually or extremely during the process of service exchange. This study provides proof in support of the common belief that customer focus strategy is a determiner of customer satisfaction.

Furthermore, customer focus strategy on employee satisfaction is due to the more able to be seen. The duties of employees within insurance sector have successfully established a culture of the customer being first. In order to execute customer focus successfully, employees need to be granted power to perform various acts and duties and provided with space for engaging customers, thus helping them to get first-hand information from clients, that serves as input for their possible improvement as employees (Mukerjee, 2013; Yu et al., 2012). Employees who are working in the insurance sector with a confidence and knowledge said to achieve a greater satisfaction towards their job. Through the practice of granting power, they feel more appreciated and valued by the firms, thus improving their job satisfaction (Aziz and Ennew, 2013).

To secure tight the result of customer focus strategy and performance of insurance sector, employee helps in the preparation and implementation stages would be required as an acknowledgment for the knowledge and skills they have in issues related to the customer. Additional, Increased levels of customer satisfaction can be attained by firms which have thoroughly internalized the principles of customer focus (Tari et al., 2013), where internalization refers to the internal motivations amongst employees that results in fuller efforts being made and more allocation of resources for the customer focus strategy. As explain in this study, customer satisfaction is also affected by customer focus strategy. Employees with high levels of achievement are highly likely to perform well in their job which in turn results in good service or that satisfies the customer (Pantouvakis and Bouranta, 2013) when customers become the main input for innovation (Alam, 2013), an innovative firm would have abundant resources to fulfill the customer demands and achieve customer satisfaction. However, this study was unable to analyze each of this measurement in a wide manner. 


\section{Conclusions and Recommendation}

This study establishes the sufficient effect that customer focus strategy has the each of the attribute's effectiveness and innovation, employee's satisfaction and customer satisfaction. In other words, this research provides indication for the benefit of customer focus strategy on performance of insurance sector whilst within most dissatisfied customers tend to take their business elsewhere, this is not necessarily the case when it comes to Insurance sector partners known as insurance companies. Nonetheless, this study provides evidence suggesting that customer focus strategy brings about positive effects on performance of insurance sector in Rwanda

Future studies may emphases more thoroughly on these factors. As such, a valid question for future researchers concerns the type of effectiveness and innovation (whether in terms of products \& services or processes) that is likely to have the most important effect on customer focus and invest in early warning systems on safety to avert disaster and create product effectiveness and innovativeness connectivity that offers updates, grants awards and generates feedback from customers.

\section{References}

i. Adebanjo, D., \& Kehoe, D. (2010). An evaluation of factors influencing teamwork and customer focus. Managing Service Quality, 11(1), 49-56.

ii. Alam, I. (2013). Customer interaction in service innovation: Evidence from India. International Journal of Emerging Markets, 8(1), 41-64.

iii. Anaza, N.A., \& Rutherford, B. (2012). How organizational and employee-customer identification, and customer orientation effect job engagement. Journal of Service Management, 23(5), 616-639.

iv. Chotekorakul, W, \& Nelson, J. (2013). Customer orientation, merchandising competencies, and financial performance of small fashion retailers in Bangkok. Journal of Fashion Marketing and Management, 17(2), 225242.

v. Dadfar, H., Brege, S., \& Semnani, S. S. E. (2013). Customer involvement in service production, delivery and quantity: The challenges and opportunity. International Journal of Quality and Service Science, 5(1), 46-65.

vi. Fonseca, F., Pinto, S., \& Brito, C. (2010). Service quality and customer satisfaction in public transports. International Journal of Quality Research, 4(2), 125-130.

vii. Hair, J.F., Anderson, R.E., Tatham, R.L., \& Black, W. C. (1998). Multivariate Data Analysis. 5th Ed. Prentice Hall: USA

viii. Corresponding author: Zulnaidi Yaaco ,2014 International Journal for Quality Research 8(2) the direct and indirect effects of customer focus on performance in public firms

ix. Zhu, D., Lin, C., Tsai, C., \& Wu, J. (2010). A study on the evaluation of customer's satisfaction- the perspective of quality. International Journal of Quality Research, 4(2), 105116.

x. Verhoef, P.C., \& Lemon, K.N. (2013). Successful customer value management: Key lesson and emerging trends. European Management Journal, 31, 1-15.

xi. Tajeddini, K., Elg, U., \& Trueman, M. (2013). Efficiency and effectiveness of small retailers: the role of customer and entrepreneurial orientation. Journal of Retailing and Consumer Services, 20, 453-462.

xii. Sun, K., \& Kim, D. (2013). Does customer satisfaction increase firm performance? An application of American Customer Satisfaction Index (ACSI). International Journal of Hospitality Management, 35, 68-77.

xiii. Steven, A.B., Dong, Y., \& Dresner, M. (2012). Linkages between customer service, customer satisfaction, and performance in the airline industry: Investigation of non-linearities and moderating effects. Transportation Research Part E, 48, 743-754

xiv. Lado, A.A., Paulraj, A., \& Chen, I. J. (2011). Customer focus, supply chain relational capabilities and performance. The International Journal of Logistic Management, 22(2), 202221.

xv. Krivokapic, Z., Vujovic, A., Jovanovic, J., Petrovis, S., \& Pekovic, S. (2013). A review and analysis concerning the effects of quality on innovation performance. International Journal of Quality Research, 7(1), 5-1

xvi. Kim, D., Kumar, V., \& Kumar, U. (2012). Relationship between quality management practices and innovation. Journal of Operations Management, 30, 295-315.

xvii. Odhiambo, 0. (2009). Implementation of performance contracting in Kenya, International Public Management Review. 10(2), 60-84.

xviii. Wabita, J. (2013) Determinants of Financial Performance of Insurance Companies in Kenya. 